\title{
Structure-reactivity relationships in $\mathrm{VO}_{x} / \mathrm{TiO}_{2}$ catalysts for the oxyhydrative scission of 1-butene and $n$-butane to acetic acid as examined by in situ- spectroscopic methods and catalytic tests
}

\author{
Ursula Bentrup $^{\mathrm{a} *}$, Angelika Brückner ${ }^{\mathrm{a}}$, Martin Fait ${ }^{\mathrm{a}}$, Bernd Kubias ${ }^{\mathrm{b}}$, Jean Boris Stelzer \\ ${ }^{a}$ Institut für Angewandte Chemie Berlin-Adlershof e.V., Berlin, Germany \\ ${ }^{\mathrm{b}}$ Fritz-Haber-Institut der Max-Planck-Gesellschaft, Berlin, Germany \\ ${ }^{c}$ Universität Hannover, Institut für Physik, Chemie und Elektrochemie, Hannover, Germany \\ ${ }^{*}$ Corresponding author. Fax: +49 3063924350.
}

\begin{abstract}
Different $\mathrm{VO}_{x} / \mathrm{TiO}_{2}$ catalyst have been catalytically tested and studied by in situ-spectroscopic methods (FT-IR, UV/vis, EPR) in the oxyhydrative scission (OHS) of 1-butene and $n$-butane to acetic acid $(\mathrm{AcOH})$. While 1-butene OHS follows the sequence butane $\rightarrow$ butoxide $\rightarrow$ ketone $\rightarrow$ $\mathrm{AcOH} /$ acetate with a multitude of side products also formed, $n$-butane OHS leads to AcOH, $\mathrm{CO}_{x}$ and $\mathrm{H}_{2} \mathrm{O}$ only. Water vapour in the feed improves $\mathrm{AcOH}$ selectivity by blocking adsorption sites for acetate. The admixture of $\mathrm{Sb}_{2} \mathrm{O}_{3}$ was found to improve $\mathrm{AcOH}$ selectivity which is due to deeper $\mathrm{V}$ reduction under steady state conditions and lowering of surface acidity. $\mathrm{VO}_{x} / \mathrm{TiO}_{2}$ catalysts with sulfate-containing anatase are the most effective ones. Covalently bonded sulfate at the catalyst surface causes specific bonding of $\mathrm{VO}_{x}$, stabilizes active $\mathrm{V}$ species and ensures their high dispersity.
\end{abstract}

Keywords: Vanadia-titania catalysts; 1-Butene; $n$-Butane; Oxyhydrative scission; In situ FT-IR; In situ UV/vis-DRS; In situ EPR

\section{Introduction}

Butenes and butanes are available as by-products of naphtha cracking for the manufacture of ethene and propene. For utilization of this cheap feedstock Wacker has developed a new cycle process in which a mixture of $n$-butane/ $n$-butene (raffinate II) is converted to acetic acid at low temperatures and under elevated pressure using vanadia containing catalysts [1]. The economic efficiency could be more improved, if the butane fraction would be oxidized with comparable conversion rate as butene. For this reason, additional knowledge about both the influence of different reaction conditions and the specific structure of active catalyst components and their role in the reaction mechanism is necessary to develop more effective catalysts with good performance.

Takita et al. [2] proposed a oxyhydrative scission (OHS) mechanism for the oxidation of butene to acetic acid. According to this, methyl ethyl ketone is initially formed by oxyhydration of the olefin and is consecutively subjected to oxidative $\mathrm{C}-\mathrm{C}$ bond scission. As result of this reaction acetic acid and acetaldehyde are obtained, whereas the latter is subsequently oxidized to acetic acid.

Other investigations have demonstrated that catalytic activity and selectivity depend on the extent of vanadium loading and the oxidation state of the catalytically active vanadium species [3], [4] and [5]. Recent own investigations [6], [7] and [8] evidenced that only catalysts with 
vanadia supported on redox active oxides such as $\mathrm{TiO}_{2}$ act effectively in the OHS of 1-butene to acetic acid whereas the vanadia content is of subordinate importance.

The investigations presented in this paper are focused on the influence of various $\mathrm{TiO}_{2}$ (anatase) materials with different sulfate contents on the activity of $\mathrm{VO}_{x} / \mathrm{TiO}_{2}$ catalysts in the OHS reaction. Furthermore, the effects of water vapour and $\mathrm{Sb}$ admixture in this reaction are described. In addition to catalytic tests, the catalysts were studied under reaction-like conditions by spectroscopic in situ-methods (FT-IR, EPR, UV-vis-DRS) using 1-butene, $n$-butane and the intermediate 2-butanol as reactants.

\section{Experimental}

The catalysts have been prepared: (1) by spray drying (sd) of oxide mixtures $\mathrm{V}_{2} \mathrm{O}_{5} / \mathrm{TiO}_{2}$ and $\mathrm{V}_{2} \mathrm{O}_{5} / \mathrm{Sb}_{2} \mathrm{O}_{3} / \mathrm{TiO}_{2}(\mathrm{~V} / \mathrm{Ti}-\mathrm{M}, \mathrm{V} / \mathrm{Sb} / \mathrm{Ti}-\mathrm{M})$; (2) by impregnation (i) of the $\mathrm{TiO}_{2}$ support with vanadyl oxalate (V/Ti-M, V/Sb/Ti-M, V/SC7) or (3) by hydrolysis of a V, Sb-alkoxide mixture (V/Sb/Ti-M, V/Sb/SC3, V/Sb/SC7) in a $\mathrm{TiO}_{2} / \mathrm{CH}_{2} \mathrm{Cl}_{2}$ suspension (ao) with 0.06 wt. $\% \mathrm{~V}$ and 0.11 wt. $\% \mathrm{Sb}$ per $\mathrm{m}^{2}$ support. Commercial $\mathrm{TiO}_{2}$ materials of Millennium Chemicals (Ti-M) and Sachtleben Chemie $\mathrm{GmbH}(\mathrm{SC} 3, \mathrm{SC} 7)$ were used. All catalysts were calcined in air at $400{ }^{\circ} \mathrm{C}$ for $4 \mathrm{~h}$.

FT-IR spectra were recorded from self-supporting discs using a Bruker IFS 66 spectrometer equipped with a IR reaction cell [7]. Prior exposing to the reaction mixture ( 3 vol. $\% \mathrm{C}_{4}, 8$ vol.\% $\mathrm{O}_{2}, 3$ vol. $\% \mathrm{H}_{2} \mathrm{O} / \mathrm{N}_{2}$ ), the samples were activated in air at $400{ }^{\circ} \mathrm{C}$ for $30 \mathrm{~min}$.

EPR spectra in X-band $(v \approx 9.5 \mathrm{GHz})$ were recorded by the cw-spectrometer ELEXSYS 500$10 / 12$ (Bruker). Measurements were carried out in a home-made flow reactor connected to a gas/liquid-supplying system [9].

UV/vis spectra in diffuse reflectance mode were recorded by a Carry 400 spectrometer (VARIAN) equipped with a diffuse reflectance accessory (praying mantis, Harrick) and a respective flow cell (Harrick). Samples were pretreated in $\mathrm{O}_{2}$ flow $(5 \mathrm{ml} / \mathrm{min})$ at $200{ }^{\circ} \mathrm{C}$ for $2 \mathrm{~h}$.

Catalytic tests were performed in a fixed bed tubular reactor in the temperature range from 160 to $220{ }^{\circ} \mathrm{C}$ at a total pressure of 7 bar. The feed composition was $1.9 \mathrm{vol} \%$ 1-butene $/ 9.1 \mathrm{vol} \%$ $\mathrm{O}_{2} / 6.1-24.4$ vol.\% $\mathrm{H}_{2} \mathrm{O} / \mathrm{N}_{2}$. Product compositions were analyzed by on line-GC (GC 17A, Shimadzu) and by non-dispersive IR photometry at normal pressure. Conversion degrees and selectivities were calculated with respect to $\mathrm{C}_{4}$ concentrations in the feed.

\section{Results and discussion}

The FT-IR spectra resulting from reaction of 1-butene $/ \mathrm{O}_{2}$ and $n$-butane $/ \mathrm{O}_{2}$ on V/Ti-M (sd) at $200{ }^{\circ} \mathrm{C}$ are depicted in Fig. 1. As can be seen from the reaction of 1-butene/ $\mathrm{O}_{2}$ (Fig. 1A) already after short contact time a set of bands can be observed. The band at $1653 \mathrm{~cm}^{-1}$ is due to the $v(\mathrm{C}=\mathrm{O})$ mode of adsorbed ketone and/or acetic acid $(\mathrm{AcOH})$, whereas the bands at 1542 and $1440 \mathrm{~cm}^{-1}$ are attributed to $v_{\mathrm{as}}\left(\mathrm{COO}^{-}\right)$and $v_{\mathrm{s}}\left(\mathrm{COO}^{-}\right)$modes of probably acetate species [10]. After $10 \mathrm{~min}$, further bands at $1780 / 1845 \mathrm{~cm}^{-1}$ and around $1628 \mathrm{~cm}^{-1}$ appear, the intensities of which increase with reaction time. The latter band is assigned to a $v(\mathrm{C}=\mathrm{C})$ mode while the others are typical for adsorbed cyclic anhydrides [11]. The appearance of adsorbed acetate species may be explained by formation of acetic acid which is partly adsorbed as acetate at the catalyst surface. If the reaction is carried out in the presence of water vapor, the same adsorbed species were detected, however, essentially less anhydride species were formed [7] and [8]. Obviously, water selectively suppresses the side reaction leading to cyclic anhydride species and blocks adsorption sites. 


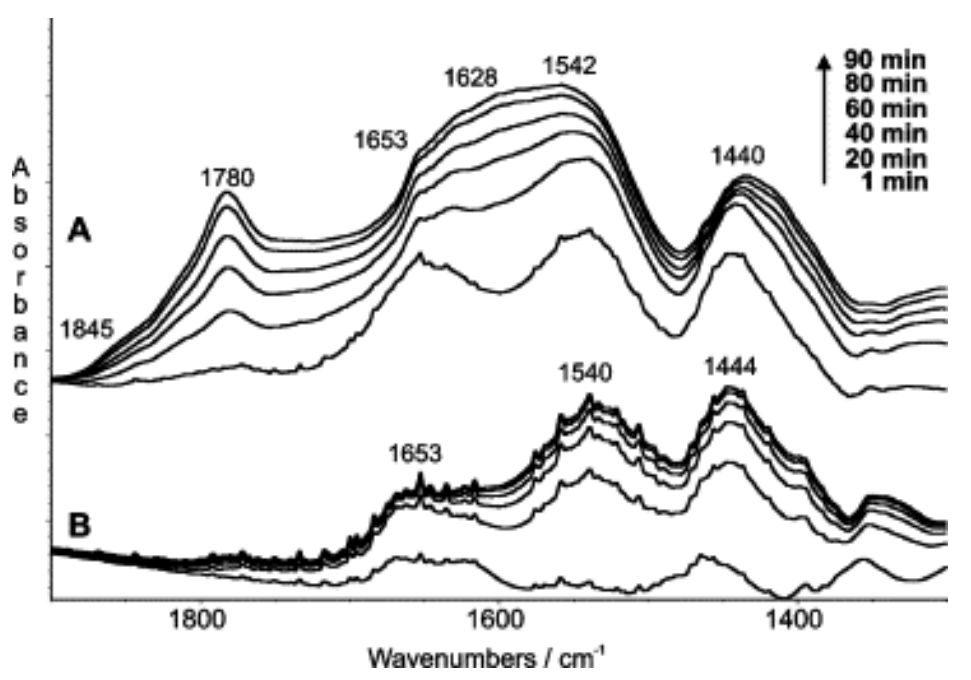

Fig. 1. FT-IR spectra of adsorbates formed on V/Sb/Ti-M (sd) during reaction of (A) 1-butene/ $\mathrm{O}_{2}$ and (B) $n$ butane $/ \mathrm{O}_{2}$ at $200{ }^{\circ} \mathrm{C}$.

As could be shown by recent investigations [6], only catalysts with vanadia supported on redox active oxides such as $\mathrm{TiO}_{2}$ act effectively in the OHS of 1-butene. To elucidate the influence of different anatase supports, $\mathrm{VO}_{x}$ catalysts with $2.2 \%$ sulfate-containing and sulfate-free anatase materials of different manufacturers were prepared. The $\mathrm{V}$-content related to the specific surface area was $0.06 \mathrm{wt} . \% \mathrm{~m}^{-2}$ for all catalysts.

More information about the redox behaviour was achieved by studying the redox kinetics using $3 \%$ 1-butene/ $\mathrm{N}_{2}$ as reducing and $9 \% \mathrm{O}_{2} / \mathrm{N}_{2}$ as oxidizing agent. UV-vis measurements have been applied to observe changes in the range for $d-d$ transitions of reduced vanadium species in dependence on time. Two pseudo-first-order processes had to be assumed for both reduction and re-oxidation [7] and [8]. Probably, the fast process (rate constant $k_{1}$ ) comprises $\mathrm{VO}_{x}$ species on the surface that are readily exposed to reactants while the slow process (rate constant $k_{2}$ ) might be related to $\mathrm{VO}_{x}$ sites in deeper layers, e.g., in the bulk of the $\mathrm{VO}_{x}$ particles. For comparison the rate constants for these two processes are listed for the catalysts $\mathrm{V} / \mathrm{Ti}-\mathrm{M}$ (sd) and V/SC7 (i) in Table 1.

Table 1.

Pseudo-first-order rate constants for reduction of $\mathrm{V}^{5+}$ in a flow of $5 \%$ 1-butene $/ \mathrm{N}_{2}$ and re-oxidation in $\mathrm{O}_{2}$.

\begin{tabular}{|l|l|l|l|l|}
\hline & \multicolumn{2}{|l|}{$k_{1}\left(1^{-3} \mathbf{m i n}^{-1}\right)$} & $k_{2}\left(1^{-3} \mathbf{m i n}^{-1}\right)$ \\
& Reduction & Re-oxidation & Reduction & Re-oxidation \\
\hline V/Ti-M (sd) & 172 & 187 & 11 & 15 \\
\hline V/SC7 (i) & 449 & 76 & 19 & 11 \\
\hline
\end{tabular}

The rate constants $k_{2}$ of $\mathrm{V}$-sites in the bulk differ only moderately. Contrarily, it is clearly seen from the rate constants $k_{1}$ that the $\mathrm{V}$-sites at the surface on V/SC7 (i) with sulfate-free support are faster reduced than on $\mathrm{V} / \mathrm{Ti}-\mathrm{M}$ (sd) with the sulfate-containing support. However, not only the rate of re-oxidation but also the percentage of re-oxidable $\mathrm{V}$ sites in V/SC7 (i) are much lower (only $24 \%$ of the $\mathrm{V}$-sites can be re-oxidized) than that of $\mathrm{V} / \mathrm{Ti}-\mathrm{M}$ (sd), which is fully reoxidized. This finding suggests an inhibition of deeper reduction of $\mathrm{V}$-sites in the equilibrium by 
sulfate present at the surface. Moreover, it could be shown by UV-vis spectra that on sulfate-free $\mathrm{V} / \mathrm{SC} 7$ (i) a distinct formation of $\mathrm{VO}_{x}$ clusters can be observed whereas on sulfate-containing $\mathrm{V} / \mathrm{Ti}-\mathrm{M}(\mathrm{sd})$ the $\mathrm{VO}_{x}$ species are markedly higher dispersed [14]. EPR and FT-IR spectroscopic measurements revealed the formation of two types of $\mathrm{VO}^{2+}$ sites on sulphated instead of only one on sulphate-free anatase and pointed to a direct bonding of a part of $\mathrm{VO}_{x}$ species to the surface sulfate groups [14].

The catalytic tests confirm these spectroscopic findings. The 1-butene conversion and $\mathrm{AcOH}$ selectivity in dependence on the catalyst temperature for different Sb-containing $\mathrm{VO}_{x} / \mathrm{TiO}_{2}$ catalysts prepared via the alkoxide method are shown in Fig. 3. The catalysts V/Sb/Ti-M (ao) and $\mathrm{V} / \mathrm{Sb} / \mathrm{SC} 3$ (ao) with sulfate-containing supports act very similar. In contrast, the catalyst $\mathrm{V} / \mathrm{Sb} / \mathrm{SC} 7$ (ao) with the sulfate-free support was essentially less active. For reaching comparable conversions the residence time has to be strongly increased. However, the estimated AcOH selectivity is proved to be much lower than that of the sulfate-containing catalyst.
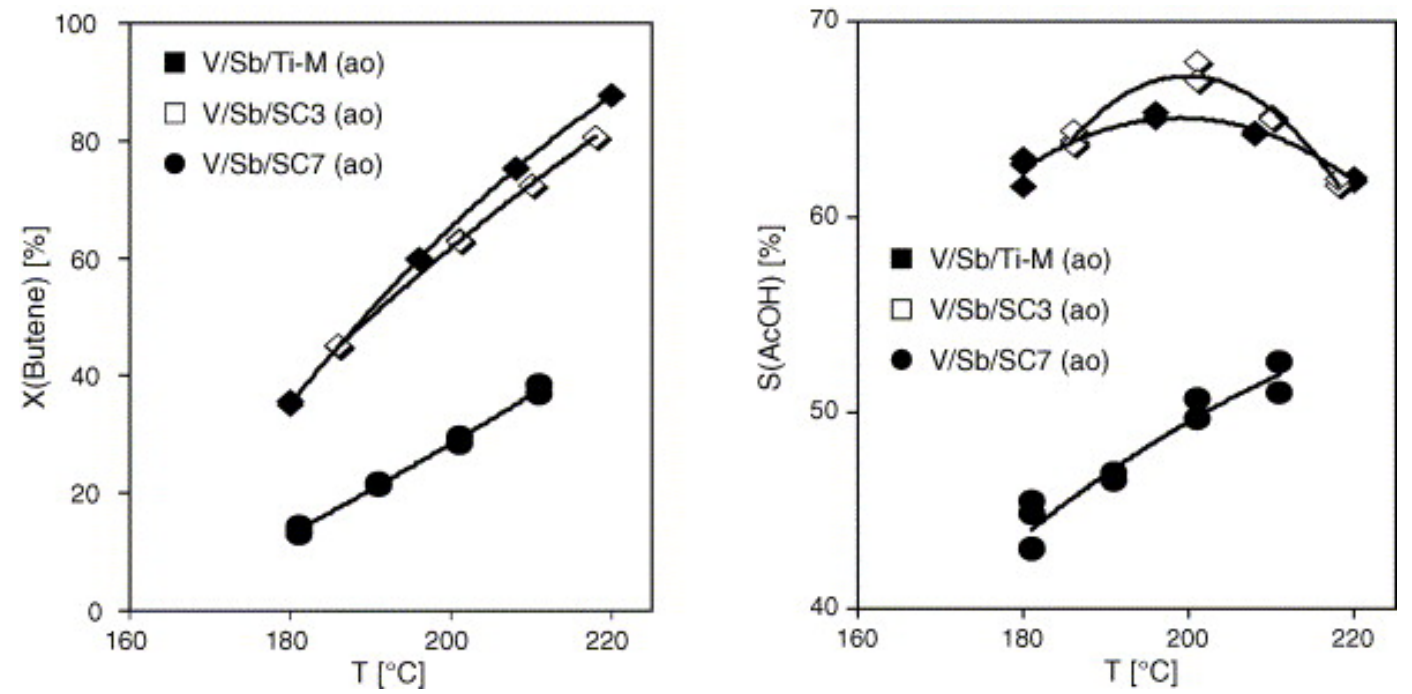

Fig. 3. Conversion of 1-butene (left) and acetic acid (AcOH) selectivity (right) as function of the catalyst temperature (feed: $1.9 \%$ 1-butene, $9.1 \% \mathrm{O}_{2}, 24.4 \% \mathrm{H}_{2} \mathrm{O} / \mathrm{N}_{2}, p=7$ bar).

\section{Conclusions}

In principle, 1-butene and $n$-butane react in the same way on $\mathrm{VO}_{x} / \mathrm{TiO}_{2}$ catalysts. However, the essential lower reactivity of $n$-butane is not markedly influenceable by varying the reaction conditions and therefore requires the separation of butane and butane OHS processes.

In situ FT-IR studies revealed that the reaction proceeds via the sequence $\mathrm{C}_{4} \rightarrow$ butoxide $\rightarrow$ ketone $\rightarrow \mathrm{AcOH} /$ acetate. Cyclic anhydride as a precursor of $\mathrm{CO}_{x}$ is formed in a side reaction. The admixture of water vapour suppresses its formation distinctly and additionally favours the desorption of acetic acid by blocking the adsorption sites for acetate. Furthermore, water vapour supports spreading of vanadia on the $\mathrm{TiO}_{2}$ surface.

The admixture of $\mathrm{Sb}_{2} \mathrm{O}_{3}$ moderates the acidity and enhances the reduction to $\mathrm{V}^{3+}$ and, thus, influences the redox behaviour of the catalysts. Both effects improve the AcOH selectivity.

The performance of $\mathrm{VO}_{x} / \mathrm{TiO}_{2}$ catalysts is markedly influenced by the nature of the support, whereas the preparation method plays a negligible role. The existence of covalently bonded sulfate at the catalyst surface is indispensable for the effective bonding of $\mathrm{VO}_{x}$ species. It stabilizes active $\mathrm{VO}_{x}$ species at the surface and ensures their high dispersity. 


\section{Acknowledgements}

The authors thank the Federal Ministry of Education and Research, Germany, for financial support (Grant No. 03C0323).

\section{References}

[1] C. Rüdinger, H.-J. Eberle, EP Patent 0,960,874 (1999).

C. Rüdinger, H.-J. Eberle, US Patent 6,281,385 (2001) to Consortium für elektrochemische Industrie $\mathrm{GmbH}$.

[2] Y. Takita, K. Nita, T. Maehara, N. Yamazoe and T. Seiyama, J. Catal. 50 (1977), p. 364.

[3] W.E. Slinkard and P.B. DeGroot, J. Catal. 68 (1981), p. 423.

[4] T. Ono, T. Mukai, H. Miyata, T. Ohno and F. Hatayama, Appl. Catal. 49 (1989), p. 273.

[5] H. Miyata, M. Kohno, T. Ono, T. Ohno and F. Hatayama, Chem. Express 4 (1989), p. 145.

[6] A. Brückner, U. Bentrup, B. Kubias, M. Fait, M. Scolari and F. Cavani, Proceedings of the 13th International Congress on Catalysis Paris, France, July 11-16 (2004).

[7] U. Bentrup, A. Brückner, C. Rüdinger and H.-J. Eberle, Appl. Catal. A: Gen. 269 (2004), p. 237.

[8] A. Brückner, U. Bentrup, M. Fait and B. Kubias, Catal. Today 99 (2005), p. 123.

[9] A. Brückner, B. Kubias, B. Lücke and R. Stößer, Colloid Surfaces 115 (1996), p. 179.

[10] V.S. Escribano, G. Busca and V. Lorenzelli, J. Phys. Chem. 95 (1991), p. 5541.

[11] G. Socrates, Infrared and Raman Characteristic Group Frequencies, John Wiley \& Sons Ltd, Chichester (2001) pp. 129-130.

[12] G. Centi and S. Perathoner, Appl. Catal. A: Gen. 124 (1995), p. 317.

[13] G. Busca, Phys. Chem. Chem. Phys. 1 (1999), p. 723. |

[14] A. Brückner, U. Bentrup and J.B. Stelzer, Z. Anorg. Allg. Chem. 631 (2005), p. 60. 